\title{
PROPERTIES OF THE TURÁNIAN OF MODIFIED BESSEL FUNCTIONS
}

\author{
ISTVÁN MEZŐ AND ÁRPÁD BARICZ
}

\begin{abstract}
In this paper some new series and integral representations for the Turánian of modified Bessel functions of the first kind are given, which give new asymptotic expansions and tight bounds for the Turán determinant in the question. It is shown that in the case of natural and real order the Turánian can be represented in a relatively compact form, which yields a uniform upper bound for the Turán determinant for modified Bessel functions of the first kind. Our results complement and improve some of the results from the literature.
\end{abstract}

Mathematics subject classification (2010): 33C10.

Keywords and phrases: Turánian, Modified Bessel functions.

\section{REFERENCES}

[1] Á. BARICZ, On a product of modified Bessel functions, Proc. Amer. Math. Soc. 137 (2009), 189-193.

[2] Á. BARICZ, Turán type inequalities for modified Bessel functions, Bull. Aust. Math. Soc. 82, 2 (2010), 254-264.

[3] Á. BARICZ, Bounds for Turánians of modified Bessel functions, Expo. Math. 33, 2 (2015), 223-251.

[4] Á. BARICZ, T. K. PogÁny, Turán determinants of Bessel functions, Forum Math. 26, 1 (2014), 295-322.

[5] Á. BARICZ, S. Ponnus amy, On Turán type inequalities for modified Bessel functions, Proc. Amer. Math. Soc. 141, 2 (2013), 523-532.

[6] J. A. Cochran, The monotonicity of modified Bessel functions with respect to their order, J. Math. Phys. 46 (1967), 220-222.

[7] C. M. Joshi, S. K. Bissu, Some inequalities of Bessel and modified Bessel functions, J. Austral. Math. Soc. Ser. A 50 (1991), 333-342.

[8] S. I. KALMYKOV, D. B. KARP, Log-concavity for series in reciprocal gamma functions and applications, Integral Transforms Spec. Funct. 24, 11 (2013), 859-872.

[9] P. A. Martin, On functions defined by sums of products of Bessel functions, J. Phys. A Math. Theor. 41 (2008), art. 015207.

[10] http://functions.wolfram.com/HypergeometricFunctions/Hypergeometric1F2/ 03/02/03/0009

[11] F. W. J. Olver, D. W. Lozier, R. F. Boisvert and C. W. Clark (Eds.), NiST Handbook of Mathematical Functions, Cambridge Univ. Press, Cambridge, 2010.

[12] H. SkovgaARd, On inequalities of the Turán type, Math. Scand. 2 (1954), 65-73.

[13] V. R. ThiRUVENKATACHAR, T. S. NANJUndiah, Inequalities concerning Bessel functions and orthogonal polynomials, Proc. Ind. Acad. Sci. Sect. A 33 (1951), 373-384.

[14] G. S. Watson, Statistics on Spheres, Wiley, New-York, 1983. 